MARTINA ZEMP University of Mannheim

FRIDTJOF W. NusSBECK Bielefeld University

E. Mark Cummings University of Notre Dame

Guy Bodenmann University of Zurich

\title{
The Spillover of Child-Related Stress into Parents' Relationship Mediated by Couple Communication
}

\begin{abstract}
Objective: The present study examines the impact of parents' perceptions of child-related stress on observed couple communication and their self-reported relationship satisfaction.

Background: A considerable body of evidence indicates that challenges related to raising children can negatively affect parents' interactions and relationship satisfaction. Although some potentially underlying mechanisms have been explored in previous research, questions about the potential effect of child-related stress on the interparental relationship remain open.
\end{abstract}

Method: Parents' perceptions of child-related stress and relationship satisfaction were assessed in a convenience sample of 118 parental couples living in Switzerland. Additionally, the couples participated in a conflict conversation task to obtain an observational measure of couples' communication quality. Data were analyzed with an actor-partner interdependence mediation model.

Results: Child-related stress among parents was directly linked to lower relationship satisfaction in both partners and one partner's

Department of Psychology, University of Mannheim, L13, 15-17, 68131 Mannheim, Germany (m.zemp@psy chologie.uni-mannheim.de).

Key Words: Children, couples, intimate relationship, parenting, stress. child-related stress was associated with the other partner's communication quality. The mediation analysis revealed that high levels of child-related stress were linked with relationship satisfaction by impairing the other partner's communication quality.

Conclusion: The study suggests that childrelated stress is among the challenges that may impair parents' relationship quality, partially mediated through worsened couple communication.

Implications: The findings support the potential benefits of prevention programs aimed at reducing child-related stress and enhancing couple coping skills for maintaining parents' relationship satisfaction over time.

Persuasive empirical support suggests that having and raising children may impair couple communication and relationship satisfaction in parents (Mitnick, Heyman, \& Smith Slep, 2009). Previous literature has documented the manifold challenges for parents as restrictions of freedom or sleep disruption, for example, that may underlie the negative effects of parenthood on the interparental relationship (e.g., Medina, Lederhos, \& Lillis, 2009; Twenge, Campbell, \& Foster, 2003). Little is known, however, about the implications of parents' perceptions of child-related stress for their relationship with 
each other. The goal of the present study is to address this paucity of research by examining the effects of child-related stress on parents' relationship satisfaction mediated by the quality of couple communication.

\section{BACKGROUND}

\section{Effects of Child Rearing on the Interparental Relationship}

Children are among the greatest sources of both joy and stress in the lives of most parents (Nelson, Kushlev, \& Lyubomirsky, 2014). Two lines of research indicate that stressors related to raising children strongly and detrimentally affect the interparental relationship. The cross-sectional approach compares relationship functioning between couples with and without children. According to a meta-analysis (Twenge et al., 2003), parents report being less satisfied in their relationships than do nonparents $(d=-0.19)$, and there is a small negative association $(r=-.06)$ between number of children and relationship satisfaction among parents. The longitudinal approach comprises transition-to-parenthood studies that focus on relationship satisfaction before and after the birth of a (usually the first) child. Meta-analyses summarizing these studies (Lawrence, Rothman, Cobb, \& Bradbury, 2010; Mitnick et al., 2009) show that parents' relationship satisfaction declines from pre- to the postnatal assessment with small to moderate aggregate effect sizes.

Apart from these well-established effects of having children on couples' relationship satisfaction, prior findings suggest that the transition to parenthood may lead to impairments in spousal interaction and communication (Belsky \& Pensky, 1988). Using observational measures of dyadic interactions in expectant parents, Belsky and colleagues (Belsky, Lang, \& Rovine, 1985; Belsky, Spanier, \& Rovine, 1983) reported that partners directed increasingly less positive behavior toward each other from the last trimester of pregnancy through the ninth postpartum month. The same pattern was found in couples' self-reported perceived positivity and satisfaction in the relationship. In a similar vein, McHale and Huston (1985) found that couples becoming parents reported reduced exchanges of positive affection after the birth of their first child compared to prebirth levels, and this decline was more pronounced than among a control group of nonparents. A more recent study (Doss, Rhoades, Stanley, \& Markman, 2009) examined couples who had their first child over the course of the first 8 years of marriage and compared them to couples who did not have children within that time span. Parents showed statistical decreases in observed communication quality and self-reported measures of relationship functioning immediately after birth. The nonparent sample perceived similar amounts of decline in overall relationship functioning over the first 8 years of marriage, but these changes tended to occur more gradually over time, without the sudden changes seen in parents following birth. Additionally, parents demonstrated statistical increases in negativity, conflict, and problem intensity after the birth of the child, whereas the nonparent group did not demonstrate statistical changes in these variables during the course of the study. The sudden nature of the negative changes following birth for parents indicates that these are likely a result of stressors related to the transition to parenthood.

The large body of literature on the potential negative impact of rearing children for the interparental relationship can perhaps be best explained by family systems theory (FST; Cox \& Paley, 2003; Minuchin, 1985). FST posits that families are organized systems and that elements within this system are interdependent; hence, behavior and affect of family members are inextricably interconnected. Rooted in the focal considerations of FST, two processes of interdependency have received considerable attention in prior research. First, ample evidence supports the spillover hypothesis, proposing that affect or behavior may transfer directly from one subsystem (e.g., the parent-child relationship) to another (e.g., the interparental relationship) within the family (e.g., Erel \& Burman, 1995, Stroud, Durbin, Wilson, \& Mendelsohn, 2011). Second, crossover processes refer to the transfer of affect or behavior between family members rather than a transfer within one person across family subsystems (Nelson, O'Brien, Blankson, Calkins, \& Keane, 2009). Crossover in couples, for instance, is said to occur when stress experienced by one partner impairs the other partner's relationship satisfaction (Bodenmann, 1997a; Neff \& Karney, 2007).

Although it is conceivable that the childrelated stress of one parent can harm his or her own and the other parent's perceived relationship 
quality (Hypothesis 1), relatively little headway has been made in the examination of spillover and crossover processes of child-related stress in parents. This is particularly surprising given that parents are exposed to many child-related stressors in their day-to-day lives, such as worries about children, negative emotions related to children and child rearing, financial strain, and organization of everyday family life (Nelson et al., 2014). According to a diary study, children were the most common source of conflict in parents (Papp, Cummings, \& Goeke-Morey, 2009). Moreover, problems with children or child rearing are among the most frequent reasons for parents to seek couple therapy (Doss, Simpson, \& Christensen, 2004). Hence, children often cause stress, which is likely to spill over into the parents' intimate relationships, according to prior research on stress in couples.

\section{The Role of Stress in Intimate Relationships}

Stress has received increased attention in couple research over the past two decades (Bodenmann, 2005). Daily stress plays a crucial role in understanding close relationships because of its inherent risk to impair relationship satisfaction and stability (Randall \& Bodenmann, 2009; Story \& Bradbury, 2004). In line with the assumptions of FST about spillover and crossover processes, empirical support is mounting that relationship-external stress (i.e., stress originating outside the relationship) may spill over into the couple's relationship, thereby undermining both partners' relationship quality over time (Bodenmann, Ledermann, \& Bradbury, 2007). Ledermann, Bodenmann, Rudaz, and Bradbury (2010) showed that the effects of stress on relationship quality were partly mediated by couple communication in self-reports. In two laboratory experiments using behavioral data, Bodenmann (1997b) found that the quality of couple communication decreased by $40 \%$ after an experimental stress induction. Specifically, couples' positive behaviors (e.g., mutual interest and empathy) were reduced and their negative interactions (e.g., criticism, contempt, and belligerence) increased under stress. Hence, as a prominent and frequent source of everyday stress in parents, child-related stress impairs communication quality between parents (Hypothesis 2), which, in turn, may mediate the deleterious impact of child-related stress on the relationship quality (Hypothesis 3). However, prior research in this realm has focused on general rather than child-related stress in parents, and on potential individual mediators but not on relationship-specific mediators. For instance, Webster-Stratton (1990) found that extrafamilial stressors led to an increase in dysfunctional parenting, mediated by the parents' reduced psychological well-being. Repetti and Wood (1997) showed that stress in the form of daily hassles disrupts mother-child interactions; on days when mothers reported greater workloads or interpersonal stress at work they were more emotionally withdrawn from their children. Furthermore, Cina and Bodenmann (2009) reported that perceived parental stress was associated with inadequate communication and dysfunctional parenting, which, in turn, predicted the child's externalizing symptoms.

In sum, most published studies about the impact of stress on relationship functioning in couples have not focused on stress related to children, although becoming parents is consistently associated with increased parental stress in everyday family life. There is no prior investigation, to our knowledge, that has examined the influence of parents' perception of child-related stress on their relationship satisfaction mediated by the quality of couple communication. The goal of the present study is to address this gap of research.

\section{The Present Study}

In this study, we examine the effects of acute child-related stress (i.e., within the preceding 7 days) perceived by parents on their communication quality and their relationship satisfaction. We hypothesized that child-related stress of both partners is negatively linked with both partners' relationship satisfaction (H1) and communication quality (H2). We further expected that communication quality in both partners mediates the impact of child-related stress on both parents' relationship satisfaction (H3). We used the actor-partner interdependence model (APIM; Ledermann, Macho, \& Kenny, 2011) to examine spillover and crossover processes. That is, we investigated the impact of child-related stress on the interparental relationship (spillover) and tested whether child-related stress of one partner also affects the other partner (crossover) by estimating partner effects (Kenny \& Cook, 1999) in the APIM. We also tested potential gender differences in the proposed effects, but could 
not specify firm hypotheses for these exploratory tests. Finally, we controlled for couples' relationship duration given its influence on couple interactions and relationship satisfaction (e.g., Lavner \& Bradbury, 2010).

\section{MethoD}

\section{Participants}

The sample comprised 118 heterosexual couples living in Switzerland who were part of a larger research project on the impact of stress on intimate relationships. Couples were recruited by advertisements in print media, on the Internet, and by radio. To be included in the larger research project, couples had to be in their current relationship for at least one year and both spouses had to be fluent in German. For the present study, the additional inclusion criterion was that couples had at least one child who was living in the same household.

The mean age was 42.4 years $(S D=7.1$, range $=23-54)$ for mothers and 44.6 years $(S D=7.2$, range $=23-56)$ for fathers. The mean relationship duration was 17.4 years $(S D=9.4$; range $=1-36)$, and the majority of the couples $(88 \%)$ were married. Twenty couples had one child (17\%), 54 had two children (45\%), 30 had three children (25\%), and 15 had four or more children $(13 \%)$. The mean age of the children was 12.8 years $(S D=6.8$, range $=1-26)$. The participants were primarily natives of Switzerland (91\% of mothers, $86 \%$ of fathers). The remaining participants were born in other European countries (8\% of mothers, $13 \%$ of fathers) or outside Europe (1\% of mothers, $1 \%$ of fathers). The highest level of education among mothers included mandatory school years (3\%), apprenticeship (41\%), high school (20\%), and college or university (36\%). The highest level of father's education included: mandatory school years (1\%), apprenticeship $(33 \%)$, high school (8\%), and college or university $(58 \%)$. The annual individual net income for $82 \%$ of mothers was less than 60,000 Swiss francs (CHF), was between 61,000 and 120,000 CHF for $15 \%$ of mothers, and $3 \%$ had annual net incomes greater than 120,000 CHF. Regarding fathers, $10 \%$ had annual individual net incomes less than 60,000 CHF, 58\% were between 61,000 and 120,000 CHF, and 32\% had annual net incomes greater than $120,000 \mathrm{CHF}$. Swiss francs and U.S. dollars have an approximate one-to-one exchange rate, so these incomes can be roughly interpreted as U.S. dollars. Thus, participants in this sample represent middle- to upper-income couples by Swiss standards.

\section{Procedure}

The data collection procedure was divided into two parts. First, couples received questionnaires via mail to complete at home. Each partner was asked to sign the consent form and was instructed to complete the questionnaires individually and independent of his or her partner. Then couples were invited to visit a university laboratory to complete a more comprehensive set of questionnaires in separate rooms (among them were the questionnaires used in this study). Additionally, the couples participated in three interaction tasks: a standard conflict conversation task and two dyadic coping tasks (an unspecified interaction in which one partner reported about a stressor). In this study, only data from the conflict conversation task were analyzed. Before the conflict conversation task started, both partners independently rated a list of 13 potential conflict topics for couples (e.g., child rearing, money) in how problematic they were in their relationship using a 4-point Likert item. They were also able to add other conflict topics to the list. The examiner then identified the most problematic topic for the couple. If partners did not agree on the major conflict topic in their relationship, the examiner tried to achieve consensus with the couple to identify a topic that affected both partners to some extent using the completed Likert items (e.g., the examiner discussed with the couple whether it is appropriate to select "money" given that the woman evaluated it as most problematic topic and the man as the second most problematic topic). The couples discussed the selected topic for 8 minutes alone in the laboratory room while being videotaped. At the end of the session, the couples received $100 \mathrm{CHF}$ for their participation.

\section{Measures}

Child-Related Stress. Parents' perceptions of child-related stress were measured by one item of the Multi-Dimensional Stress Scale for Couples (MSQ-C; Bodenmann, Schär, \& Gmelch, 2008)—specifically, the item assessing perceived stress related to children. Participants were given the following written examples to 
demonstrate areas from which child-related stress could emanate: child rearing, parenting, worries about children, restriction of freedom, activities, and dealing with children. However, we assessed child-related stress as a global stress measure without considering the given examples separately. Both parents rated child-related stress over the previous 7 days, with response options ranging from not at all stressful (1) to very stressful (4).

Relationship Satisfaction. The German version (Sander \& Böcker, 1993) of the Relationship Assessment Scale (RAS; Hendrick, 1988) was used to measure parents' relationship satisfaction. Response options on the 7 items (e.g., "How well does your partner meet your needs?") ranged from not at all (1) to extremely well (5), with higher mean scores indicating higher relationship satisfaction. The German-language RAS has previously demonstrated satisfactory reliability and validity (Sander \& Böcker, 1993), and in the present study, internal consistency (Cronbach's alpha) was $\alpha=.85$ for mothers and $\alpha=.85$ for fathers.

Communication Quality. Observational scales for communication quality (i.e., verbal positivity and verbal negativity) were adapted from the Specific Affect Coding System (SPAFF; Gottman \& Krokoff, 1989). The SPAFF is a widely used, reliable, and externally valid coding system for observing interactive affective behavior in couples (Johnson, 2002). SPAFF coding distinguishes positive affects (e.g., humor, interest, validation) from negative affects (e.g., anger, belligerence, contempt) and involves verbal content, facial behaviors, voice tones, and other forms of communication. In the present study, we focused on two categories: verbal positivity and verbal negativity. In the adapted version of the SPAFF, verbal positivity consisted of four subcategories (i.e., interest, validation, affect or caring, and constructive communication) and verbal negativity consisted of seven subcategories (i.e., criticism, defensiveness, domineering, stonewalling, formal negative interaction, contempt, and belligerence). The videotaped couple conversations were rated by two raters simultaneously, one focusing on the father, the other focusing on the mother. For intervals of 10 seconds throughout the 8-minute conversations, raters coded if a subcategory of verbal positivity or negativity was shown $(0=$ did not occur, $1=$ did occur $)$. Research assistants completed at least 60 hours of training each to master the coding system. At the end of the training period, all rater teams achieved a high interrater reliability (i.e., Cohen's kappa $\geq .90$ ). This coding system has been used in previous research (e.g., Kuster et al., 2015).

This communication quality variable was derived on the basis of previous findings suggesting that the ratio of positive to negative interactions in a couple may be a more accurate predictor of relationship outcomes than the absolute frequency of either (Gottman, 1993, 1994). Thus, ratio scores for communication quality were obtained by dividing the number of indicators for verbal positivity (possible range: 0 to 48 ) by the number of indicators for verbal negativity (possible range: 0-48) for each partner; higher scores therefore imply better communication quality. Zero could be reached if there were no positive communication, and 48 could be reached if there were one or fewer indicators of negative communication in conjunction with positive communication in each of the 48 intervals. However, it is unlikely that a partner would verbally express positivity or negativity at every 10 -second interval during 8 minutes (i.e., neutral communication is likely to occur at times as well). In cases where participants did not show any form of verbal negativity (verbal negativity $=0$ ), the numerical fractions were not defined (this was the case in $n=47$ mothers and $n=72$ fathers). We handled this computational problem by treating these cases as if they showed one indicator of negativity (verbal negativity $=1$ ) to reduce missing data.

\section{Data Analysis}

In dyadic data analysis, the term mixed variables refers to variables that can differ both across and within couples (Kenny, Kashy, \& Cook, 2006). We have mixed variables at the core interest in our study: parents' perception of child-related stress (mother and father ratings), communication quality (observational data of couple communication in the conflict conversation task), and relationship satisfaction (mother and father ratings). An actor-partner interdependence model can account for both the mixed variables and the nonindependent nature of our dyadic data. However, we also hypothesized a mediating effect, and thus tested 
an actor-partner interdependence mediation model (APIMeM; Ledermann et al., 2011; see Figure 1).

APIMeMs simultaneously estimate the effects of both partners' predictors on both partners' mediating and dependent variables as well as the indirect (mediation) effect. Effects of one individual's independent variables on their own dependent variables are called actor effects (e.g., mothers' communication quality on mothers' relationship satisfaction), whereas influences on their partners' dependent variables are called partner effects (e.g., mothers' communication quality on fathers' relationship satisfaction; Kenny \& Cook, 1999). We examined whether the effect of child-related stress reported by mothers and fathers on both parents' relationship satisfaction is mediated by both parents' communication quality (resulting in eight indirect effects). Following recent recommendations for assessing mediation in small to moderate samples, we examined the indirect effects using the bootstrap resampling procedure (MacKinnon, 2008; Shrout \& Bolger, 2002). If communication quality acts as a mediator in this model, the indirect effect of child-related stress on relationship satisfaction via communication quality would be negative and statistically significant, that is, when the upper 5\% threshold of the bootstrapped confidence interval is below 0 , given that we expected a negative indirect effect (one-tailed confidence interval given the directed study hypotheses; cf. MacKinnon, 2008). We did not use a Sobel test for mediation, as its basic definition relies on the unrealistic assumption of a normally distributed product variable $[z$ score $=a b /$ s.e. $(a b)$; with $a$ being the effect from predictor to mediator and $b$ being the effect from mediator to criterion]. Instead, resampling methods (i.e., bootstrapping) do not rely on this assumption and can handle the mediation test better (MacKinnon, 2008). Therefore, we used bootstrapping to determine whether indirect effects were statistically significant.

We statistically controlled for the duration of the couples' relationship given its potential influence on couple interactions and relationship satisfaction (e.g., Lavner \& Bradbury, 2010). Additionally, we controlled for both partners' education and income, as well as the couple's marital status, in preliminary analyses because previous studies have shown that these characteristics may be confounding variables in research on couples (Gottman, 1994; Gottman \&
Notarius, 2002). However, including education, income, and marital status as covariates did not alter the findings, so they were excluded from the final analyses for the sake of parsimony. All predictor variables were allowed to correlate among one another.

Analyses were conducted using Mplus 7.2 (Muthén \& Muthén, 1998-2015). The full information maximum likelihood (FIML) estimation procedure with bootstrap option $(10,000$ samples) implemented in Mplus was used to estimate model parameters. We inspected the goodness-of-fit of constrained models relying on multiple fit indexes: the $\chi^{2}$ test, the ratio of the $\chi^{2}$ value to its degrees of freedom $\left(\chi^{2} / d f\right.$, with values of less than 3 indicating acceptable fit), the root mean square error of approximation (RMSEA), and the comparative fit index (CFI). Values of RMSEA less than or equal to .05 and values of CFI of at least .95 indicate a good representation of the data.

\section{RESULTS \\ Preliminary Analyses}

Means, standard deviations, and correlations among all study variables are listed in Table 1. Parents statistically differed in their perceived child-related stress and communication quality: compared to fathers, mothers reported higher child-related stress $[t(116)=2.84, p=.005$, $d=0.53$ ] and scored lower in communication quality $[t(117)=-4.44, p<.001, d=0.82]$. Reported levels of relationship satisfaction tended to be high $(M=4.29, S D=0.52$ in mothers and $M=4.32, S D=0.47$ in fathers, based on a 5-point Likert-type set of response options). Couples also had a relatively high ratio of positive-to-negative communication in their observed conversations $(M=5.50$, $S D=6.08$, range $=1-25$ in mothers and $M=8.81, S D=7.78$, range $=1-29$ in fathers).

Communication quality and relationship satisfaction correlated positively for both mothers and fathers. Fathers' perception of child-related stress was negatively associated with their own relationship satisfaction and relationship duration. All study variables intercorrelated positively between mothers and fathers (entries on the main diagonal in Table 1). The frequencies of the selected topics for the videotaped conflict conversation tasks were the following: children (22\%), couple communication (16\%), money 
FigURE 1. ACTOR-PARTNER INTERDEPENDENCE MEDIATION MODEL (APIMEM) OF THE IMPACT OF CHILD-RELATED STRESS ON PARENTS' RELATIONSHIP SATISFACTION MEDIATED BY COMMUNICATION QUALITY, WHILE CONTROLLING FOR COUPLES' RELATIONSHIP DURATION.

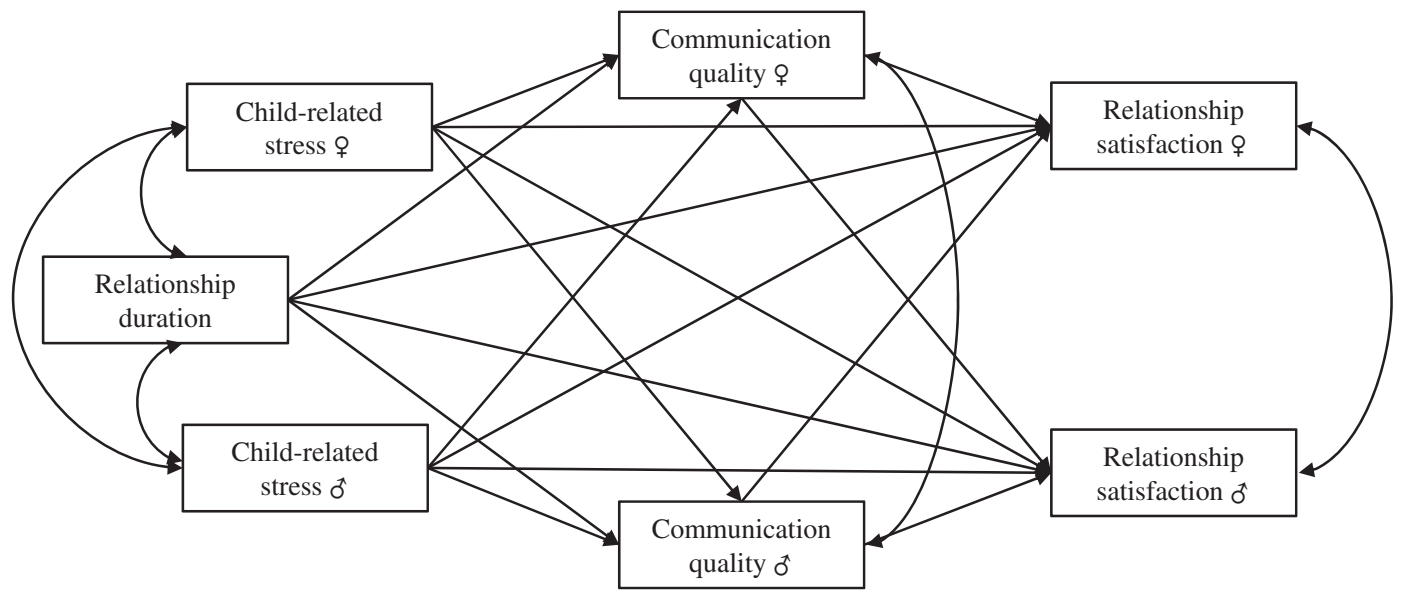

Table 1. Means, Standard Deviations, and Correlations Among Study Variables

\begin{tabular}{|c|c|c|c|c|c|c|}
\hline & \multicolumn{2}{|c|}{ Descriptives } & \multicolumn{4}{|c|}{ Bivariate correlations } \\
\hline & Mothers $M(S D)$ & Fathers $M(S D)$ & 1 & 2 & 3 & 4 \\
\hline 1. Child-related stress & $2.23(0.90)$ & $1.97(0.83)$ & $.37^{* * *}$ & -.06 & $-.26^{* *}$ & $-.21^{*}$ \\
\hline 2. Communication quality & $5.50(6.08)$ & $8.81(7.78)$ & -.04 & $.34^{* * *}$ & $.26^{* *}$ & .02 \\
\hline 3. Relationship satisfaction & $4.29(0.52)$ & $4.32(0.47)$ & -.14 & $.27^{* *}$ & $.51^{* * *}$ & -.01 \\
\hline 4. Relationship duration & $17.38(9.35)$ & $17.38(9.35)$ & $-.17^{\dagger}$ & -.07 & .01 & - \\
\hline
\end{tabular}

Note. Correlations above the diagonal are fathers' and under the diagonal are mothers'; intercorrelations between genders are on the diagonal (bold).

${ }^{\dagger} p<.10,{ }^{*} p<.05,{ }^{* *} p<.01,{ }^{* * *} p<.001$ (two-tailed).

$(11 \%)$, leisure activities (10\%), family of origin $(9 \%)$, annoying habits of the partner (6\%), values and attitudes $(5 \%)$, sexuality and/or intimacy $(4 \%)$, friends $(3 \%)$, consumer behavior $(3 \%)$, jealousy (3\%), and attractiveness of the partner (3\%); unlisted topics were selected by $5 \%$ of couples.

We first ran a fully saturated APIMeM (Model 0 ) as illustrated in Figure 1, and then tested that model against models with parameter constraints. In Model 1, we restricted the actor effects of relationship duration on communication quality and on relationship satisfaction to be equal within mothers and within fathers, respectively. We also restricted the actor and partner effects of communication quality on relationship satisfaction to be equal across genders. Model 1 fit the data well $\left[\chi^{2}(4)=2.82, p=.588\right.$; $\chi^{2} / d f=.71 ;$ RMSEA $=.00 ;$ CFI $\left.=1.00\right]$.

Next, we restricted mothers' and fathers' actor and partner effects of child-related stress on communications quality and, likewise, the actor and partner effects of child-related stress on relationship satisfaction to be equal across genders (Model 2). This model still fit the data well $\left[\chi^{2}(8)=7.67, p=.467 ; \chi^{2} / d f=.96\right.$; RMSEA $=.00 ;$ CFI $=1.00]$. Parameter estimates of Model 2 are depicted in Tables 2 and 3. Overall, the predictors in Model 2 explained $R^{2}=.13$ of the variance in relationship satisfaction for mothers and $R^{2}=.16$ for fathers.

\section{Direct Effects}

As listed in Table 2, one partner's child-related stress predicted both partners' relationship satisfaction (actor effect: $b=-0.08$ and partner effect: $b=-0.08)$. Interestingly, child-related stress did not predict one's own but the partner's communication quality $(b=-0.90)$. Communication quality of one partner predicted both 
Table 2. Parameter Estimates for Correlations and Direct Paths of the APIMeM Depicted in Figure 1

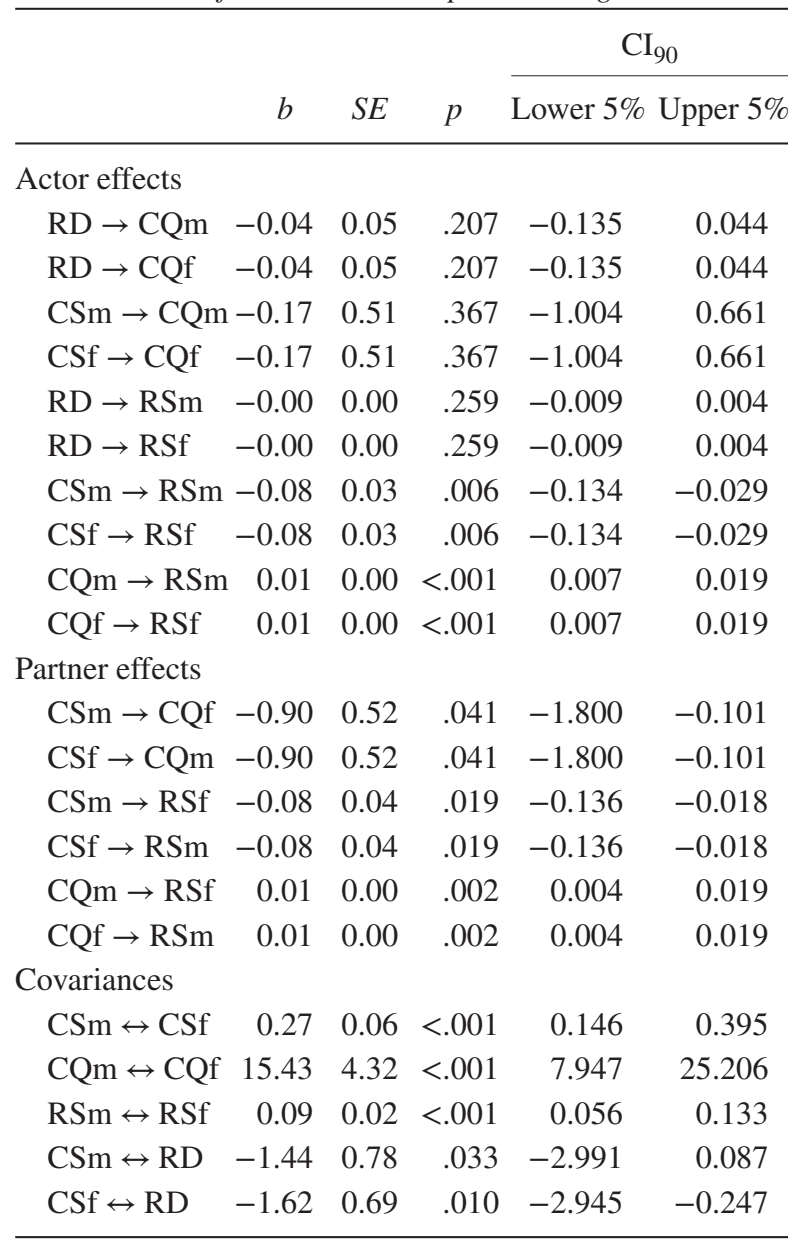

Note. Parameter estimates are unstandardized coefficients. $\mathrm{CS}=$ child-related stress; $\mathrm{CQ}=$ communication quality; $\mathrm{RS}=$ relationship satisfaction; $\mathrm{RD}=$ relationship duration; $\mathrm{m}=$ mothers; $\mathrm{f}=$ fathers.

partners' relationship satisfaction (actor effect: $b=0.01$ and partner effect: $b=0.01$ ). There was no statistical association between couples' relationship duration and either communication quality or relationship satisfaction in both partners.

\section{Indirect Effects}

As depicted in Table 3, four of the eight indirect effects of child-related stress on parents' relationship satisfaction through communication quality were statistically significant. One's relationship satisfaction was predicted indirectly by one's own child-related stress but only via the partner's communication quality $(b=-0.01)$. That is, fathers' communication quality mediated the effect of mothers' perception of child-related stress on mothers' relationship
Table 3. Parameter Estimates for Indirect Paths of the APIMeM Depicted in Figure 1

\begin{tabular}{lrrrr}
\hline & \multicolumn{4}{c}{ Bootstrap confidence intervals } \\
\cline { 2 - 5 } & Lower 5\% & Estimate & Upper 5\% & $p$ \\
\hline $\mathrm{CSm} \rightarrow \mathrm{CQm} \rightarrow \mathrm{RSm}$ & -.015 & -.002 & .007 & .373 \\
$\mathrm{CSf} \rightarrow \mathrm{CQf} \rightarrow \mathrm{RSf}$ & -.015 & -.002 & .007 & .373 \\
$\mathrm{CSm} \rightarrow \mathrm{CQf} \rightarrow \mathrm{RSm}$ & -.027 & $\mathbf{- . 0 1 0}$ & -.002 & .079 \\
$\mathrm{CSf} \rightarrow \mathrm{CQm} \rightarrow \mathrm{RSf}$ & -.027 & -.010 & -.002 & .371 \\
$\mathrm{CSm} \rightarrow \mathrm{CQm} \rightarrow \mathrm{RSf}$ & -.012 & -.002 & .008 & .371 \\
$\mathrm{CSf} \rightarrow \mathrm{CQf} \rightarrow \mathrm{RSm}$ & -.012 & -.002 & .008 & .371 \\
$\mathrm{CSm} \rightarrow \mathrm{CQf} \rightarrow \mathrm{RSf}$ & -.027 & -.011 & -.003 & .052 \\
$\mathrm{CSf} \rightarrow \mathrm{CQm} \rightarrow \mathrm{RSm}$ & -.027 & $\mathbf{- . 0 1 1}$ & -.003 & .052 \\
\hline
\end{tabular}

Note. Parameter estimates are unstandardized coefficients. Mediation is said to occur when the indirect effect of child-related stress on relationship satisfaction via communication quality is negative and statistically significant (Hypothesis 3); that is, when the upper 5\% threshold of the bootstrapped confidence interval is below 0 given that we expected a negative indirect effect (one-tailed confidence interval). Statistically significant values are in bold. $\mathrm{CS}=$ child-related stress; $\mathrm{CQ}=$ communication quality; $\mathrm{RS}=$ relationship satisfaction; $\mathrm{RD}=$ relationship duration; $\mathrm{m}=$ mothers; $\mathrm{f}=$ fathers.

satisfaction. Similarly, mothers' communication quality mediated the effect of fathers' child-related stress on fathers' relationship satisfaction. Additionally, one's relationship satisfaction was predicted indirectly by the partner's child-related stress but only via one's own communication quality $(b=-0.01)$. That is, fathers' communication quality mediated the effect of mothers' child-related stress on fathers' relationship satisfaction. Similarly, mothers' communication quality mediated the effect of fathers' child-related stress on mothers' relationship satisfaction.

\section{DiscUSSION}

The goal of the present study was to examine the effects of parent reports of child-related stress on parents' relationship satisfaction assessed by questionnaires (H1) and on interparental communication observed in couple conversations $(\mathrm{H} 2)$. We further tested whether communication quality mediated the link between child-related stress and relationship satisfaction (H3). The first hypothesis examining the impact of child-related stress on parents' relationship satisfaction received strong support from our data; parent reports of child-related stress were 
statistically related to their own as well as to their partners' relationship satisfaction. This result replicates findings about the deleterious overflow of stress into the intimate relationship leading to reduced satisfaction in couples (for an overview, see Randall \& Bodenmann, 2009; Story \& Bradbury, 2004). In terms of the FST, it is an example of a spillover process (Erel \& Burman, 1995) showing a transfer of affects from one family subsystem, in this instance the parent-child relationship, to another subsystem, the interparental relationship.

The second hypothesis was partially supported; although actor effects were not found in this regard, the partner effects of one partner's child-related stress on the other partner's communication quality were statistically significant. This finding implies a couple crossover process (Neff \& Karney, 2007) showing that mothers' perceived stress related to children may impair the father's communication quality, and vice versa. This is consistent with previous research showing that one partner's communication was affected by the other partner's perceived stress (Ledermann et al., 2010; Nelson et al., 2009). It is conceivable that partners sense the other partners' feelings of stress and attribute them to themselves (Abramson, Seligman, \& Teasdale, 1978) and thus communicate more negatively as a form of reaction or defense. The stressed partner, in contrast, is aware of the primary source of his or her stress (e.g., children), which is, albeit within the family system, not genuinely within the parental dyad. As a result, the stressed partner does not show deterioration in couple communication. These findings highlight the importance of a dyadic approach when examining the impact of stress in couples.

The mediation hypothesis (H3) was partially supported; our results suggest that high levels of child-related stress in one partner are important for predicting the relationship satisfaction of both partners by impairing the other partner's communication quality. Hence, these findings are consistent with prior reports that (relationship-external) stressors may be directly associated with relationship distress, as well as indirectly associated through worsened couple communication (Bodenmann, 1997b; Ledermann et al., 2010), and extends this finding to child-related stress in parents.

In summary, our findings yield evidence for the (a) spillover of affects across family subsystems (from the parent-child relationship to the interparental relationship) and (b) crossover processes (interrelations between mothers and fathers) that parents may encounter as a product of child-related stress. Although in the total model the explained variance in relationship satisfaction for mothers and fathers indicated medium effects according to Cohen (1988), reported regression coefficients were, albeit statistically significant, fairly small. However, given the operationalization of communication quality in this study, we note that with an unstandardized regression coefficient of 0.01 , relationship satisfaction increases 0.48 scale points when the ratio score for communication quality is maximal $($ ratio $=48$ ). To illustrate its practical meaning, this equals one standard deviation in relationship satisfaction.

Previous research has successfully begun to investigate the various challenges parents face that may explain the negative impact of parenthood on a couples' relationship, including restriction of freedom, role conflicts, sexual dissatisfaction, financial stress, and sleep disruption (Medina et al., 2009; Twenge et al., 2003). The present study adds to this knowledge to the extent that it provides evidence for the role of perceived child-related stress in decreasing relationship quality of parents, partially mediated through impaired couple communication. With $22 \%$ of couples choosing to talk about children in the conflict conversation task, children were the most frequent topic of disagreement among couples in our sample (see also Papp et al., 2009). Hence, children and stress stemming from parenting were the most frequent and burdensome sources of conflict in these parents' everyday lives. By the same token, it must be considered that the mean positive-to-negative ratios in our sample (again, 5.50 for mothers and 8.81 for fathers) appear relatively high compared to prior studies that have consistently found ratios of approximately 5.0 for regulated (relatively high functioning) couples (Gottman, 1993; Gottman \& Levenson, 1992).

Most of the children of the participating couples were (early) adolescents. This stage of child development is often linked to high levels of parental stress given the numerous changes in parent-child relationships (Collins \& Laursen, 2004; De Goede, Branje, \& Meeus, 2009). For example, increasing autonomy in adolescents often leads to decreasing emotional closeness with parents, parent-adolescent relationships becoming more egalitarian and reciprocal, a 
high amount of parent-child conflicts, parental worries about children's activities and whereabouts, and interparental disagreements about parenting topics or challenges concerning cooperation in child rearing between parents (i.e., coparenting; McHale \& Lindahl, 2011). However, the single-item method of assessing child-related stress in the present study precludes us from having detailed information about which type of stressors related to children were most detrimental for couple communication and relationship satisfaction, or whether the developmental stage of the children moderated the effects. Replication and expansion of the present study to address these research questions seem worthwhile.

We found no gender differences with regard to the main findings, although we did not specify directed hypotheses in this regard as this part of the study was exploratory. Although mothers reported higher mean levels of child-related stress than fathers did, the sequelae thereof in terms of couple functioning seems to be largely comparable between genders. This, however, is inconsistent with prior research indicating that fathers are more susceptible to spillover effects between the interparental relationship and parent-child relations (e.g., Davies, Sturge-Apple, Woitach, \& Cummings, 2009; Kouros, Papp, Goeke-Morey, \& Cummings, 2014). We assume that mothers, given that they still prevalently hold the primary caregiver function for children and spend more time with them than fathers, might be better able to compartmentalize their spousal versus their parenting role, thereby reducing the risk of negative spillover from one domain into the other. However, caution is warranted when comparing our findings with those other reports given that we did not assess parent-child interactions, but parent-reports of their perceived stress related to children. Future research is needed to further examine potential gender differences in this regard.

\section{Practical Implications}

The findings reported here have many practical implications. Considering that parents usually face particularly high levels of stress in the everyday family setting, efforts should be made to reduce and deal with stress among parents to foster and maintain relationship satisfaction over time. Finding effective ways to cope with daily stressors individually and together as a couple seems crucial to minimizing the spillover of stress into the intimate relationship. Intervention approaches that teach couples about the potentially toxic impact of stress and aim to enhance individual and dyadic stress coping skills, such as the Couples Coping Enhancement Training (CCET; Bodenmann \& Shantinath, 2004), have generated auspicious results (e.g., Ledermann, Bodenmann, \& Cina, 2007). Taking a familywide perspective, previous findings demonstrated that parents' participation in CCET led to statistical decreases in child problem behavior (Bodenmann, Cina, Ledermann, $\&$ Sanders, 2008), and these effects were mediated by enhancing the couple's relationship quality in mothers, and by improving parenting in fathers (Zemp, Milek, Cummings, Cina, \& Bodenmann, 2016). Although these findings are promising, the dearth of research on prevention programs tailored for parents to enhance skills for handling stress is a major gap to which more effort should be devoted. There are treatments emerging, however, that address the goal of effective coparenting; that is, how parents cooperate in child rearing, support each other in their parenting efforts, and manage child-related conflicts (Feinberg, 2002; McHale \& Lindahl, 2011). Growing evidence supports the efficacy of coparenting-focused interventions in terms of couple functioning and child well-being (e.g., Feinberg et al., 2016; McHale, Salman-Engin, \& Coovert, 2015), and it can be assumed that they also help reduce parental child-related stress. Although causation cannot be determined, decreasing stress in parent-child interactions may also reduce interparental conflict. The enhancement of parents' self-efficacy and parenting skills, for instance by parenting programs such as the Triple $\mathrm{P}$-Positive Parenting Program (Sanders, 1999), can reduce parents' level of frustration and stress when interacting with their children, which may foster parental relationship satisfaction over time (Zemp, Milek, Davies, \& Bodenmann, 2016).

\section{Study Limitations}

Interpretation of the present study must be qualified by several caveats. First, and most important, is the correlational nature of the study, which does not allow conclusions to be drawn about (a) direction (causality) of the associations between study variables or (b) the long-term 
influences of parents' child-related stress on their intimate relationship. Thus, research is needed that employs more sophisticated research designs, including longitudinal studies. Second, we acknowledge the methodological limitation posed by measuring parents' child-related stress with one item; our exploratory findings underscore the importance of more comprehensively assessing parents' child-related stress in future work (e.g., by measuring specific areas related to children that are perceived as stressful or by including observational data of parent-child interactions). Third, generalizability of our results are limited given the relatively high income and above-average level of education of couples (in particular fathers) who participated in the present study. Likewise, participants tended to report high relationship satisfaction and communicated very constructively with positivity outperforming negativity many times over, as indicated by the high positive-to-negative ratios in women and men. Although the observed effects were generally small to medium, this may be partly attributable to the high-functioning couples that formed our sample. Caution is warranted when generalizing our findings to less privileged families and more distressed couples. Fourth, the conflict topics couples discussed were selected on the basis of a rating list of possibly stressful topics, and we were not able to control whether the effects were different depending on the chosen topic. It is conceivable that the communication quality of couples high in child-related stress is particularly vulnerable when discussing child-related conflicts.

\section{Conclusion}

With the aforementioned limitations in mind, the present study provides evidence that child-related stress is among the many challenges parents have to deal with in everyday family life and, more specifically, might be among the precursors of impaired or less positive couple communication. This, in turn, appears to be one of the possible explanatory mechanisms for the well-established finding that raising children affects parents' relationship satisfaction. More generally, stress and coping is an area of research that has immanent potential to spur targeted treatments for parents, for the sake of the whole family.

\section{Author Note}

This study has been funded by a grant of the Swiss National Science Foundation (SNSF: CRSI11_133004/1) to Guy Bodenmann, Veronika Brandstätter, Mike Martin, and Fridtjof W. Nussbeck.

\section{REFERENCES}

Abramson, L. Y., Seligman, M. E., \& Teasdale, J. D. (1978). Learned helplessness in humans: Critique and reformulation. Journal of Abnormal Psychology, 87, 49-74. https://doi.org/10.1037/0021843X.87.1.49

Belsky, J., Lang, M. E., \& Rovine, M. (1985). Stability and change in marriage across the transition to parenthood: A second study. Journal of Marriage and the Family, 47, 855-865. https://doi.org/ $10.2307 / 352329$

Belsky, J., \& Pensky, E. (1988). Marital change across the transition to parenthood. Marriage \& Family Review, 12(3-4), 133-156. https://doi.org/10 .1300/J002v12n03_08

Belsky, J., Spanier, G. B., \& Rovine, M. (1983). Stability and change in marriage across the transition to parenthood. Journal of Marriage and Family, 45, 567-577. https://doi.org/10.2307/351661

Bodenmann, G. (1997a). Dyadic coping: A systemictransactional view of stress and coping among couples: Theory and empirical findings. European Review of Applied Psychology, 47, 137-140.

Bodenmann, G. (1997b). The influence of stress and coping on close relationships: A two-year longitudinal study. Swiss Journal of Psychology, 56, 156-164.

Bodenmann, G. (2005). Dyadic coping and its significance for marital functioning. In T. A. Revenson, K. Kayser, \& G. Bodenmann (Eds.), Couples coping with stress: Emerging perspectives on dyadic coping (pp. 33-50). Washington, DC: American Psychological Association.

Bodenmann, G., Cina, A., Ledermann, T., \& Sanders, M. R. (2008). The efficacy of the Triple PPositive Parenting Program in improving parenting and child behavior: A comparison with two other treatment conditions. Behaviour Research and Therapy, 46, 411-427. https://doi.org/10 $.1016 /$ j.brat.2008.01.001

Bodenmann, G., Ledermann, T., \& Bradbury, T. N. (2007). Stress, sex, and satisfaction in marriage. Personal Relationships, 14, 551-569. https://doi .org/10.1111/j.1475-6811.2007.00171.x

Bodenmann, G., Schär, M., \& Gmelch, S. (2008). Multi-dimensionaler Stressfragebogen für Paare $(M D S-P)$. [Multi-dimensional stress scale for couples (MSQ-C)]. Unpublished manuscript. Zurich, Switzerland: University of Zurich. 
Bodenmann, G., \& Shantinath, S. D. (2004). The Couples Coping Enhancement Training (CCET): A new approach to prevention of marital distress based upon stress and coping. Family Relations, 53, 477-484. https://doi.org/10.1111/j.0197-6664 .2004.00056.x

Cina, A., \& Bodenmann, G. (2009). Zusammenhang zwischen Stress der Eltern und kindlichem Problemverhalten [Relationship between parental stress and child problem behavior]. Kindheit und Entwicklung, 18, 39-48. https://doi.org/10.1026/ 0942-5403.18.1.39

Cohen, J. (1988). Statistical power analysis for the behavioral sciences (Vol. 2). Hillsdale, NJ: Erlbaum.

Collins, W. A., \& Laursen, B. (2004). Parentadolescent relationships and influences. In R. M. Lerner \& L. Steinberg (Eds.), Handbook of adolescent psychology (pp. 331-361). Hoboken, NJ: Wiley.

Cox, M. J., \& Paley, B. (2003). Understanding families as systems. Current Directions in Psychological Science, 12, 193-196. https://doi.org/10.1111/ 1467-8721.01259

Davies, P. T., Sturge-Apple, M. L., Woitach, M. J., \& Cummings, E. M. (2009). A process analysis of the transmission of distress from interparental conflict to parenting: Adult relationship security as an explanatory mechanism. Developmental Psychology, 45, 1761-1773. https://doi.org/10.1037/ a0016426

De Goede, I. H. A., Branje, S. J. T., \& Meeus, W. H. J. (2009). Developmental changes in adolescents' perceptions of relationships with their parents. Journal of Youth and Adolescence, 38, 75-88. https://doi.org/10.1007/s10964-008-9286-7

Doss, B. D., Rhoades, G. K., Stanley, S. M., \& Markman, H. J. (2009). The effect of the transition to parenthood on relationship quality: An 8-year prospective study. Journal of Personality and Social Psychology, 96, 601-619. https://doi .org/10.1037/a0013969

Doss, B. D., Simpson, L. E., \& Christensen, A. (2004). Why do couples seek marital therapy? Professional Psychology: Research and Practice, 35, 608-614. https://doi.org/10.1037/0735-7028.35.6.608

Erel, O., \& Burman, B. (1995). Interrelatedness of marital relations and parent-child relations: A meta-analytic review. Psychological Bulletin, 118, 108-132. https://doi.org/10.1037/0033-2909.118 .1 .108

Feinberg, M. E. (2002). Coparenting and the transition to parenthood: A framework for prevention. Clinical Child and Family Psychology Review, 5, 173-195. https://doi.org/10.1023/A: 1019695015110

Feinberg, M. E., Jones, D. E., Hostetler, M. L., Roettger, M. E., Paul, I. M., \& Ehrenthal, D. B. (2016). Couple-focused prevention at the transition to parenthood, a randomized trial: Effects on coparenting, parenting, family violence, and parent and child adjustment. Prevention Science, 17, 751-764. https://doi.org/10.1007/s11 121-016-0674-z

Gottman, J. M. (1993). The roles of conflict engagement, escalation, and avoidance in marital interaction: A longitudinal view of five types of couples. Journal of Consulting and Clinical Psychology, 61, $6-15$.

Gottman, J. M. (1994). What predicts divorce? The relationship between marital processes and marital outcomes. Hillsdale, NJ: Erlbaum.

Gottman, J. M., \& Krokoff, L. J. (1989). Marital interaction and satisfaction: A longitudinal view. Journal of Consulting and Clinical Psychology, 57, 47-52. https://doi.org/10.1037/0022-006X.57 .1 .47

Gottman, J. M., \& Levenson, R. W. (1992). Marital processes predictive of later dissolution: Behavior, physiology, and health. Journal of Personality and Social Psychology, 63, 221-233. https://doi.org/ 10.1037/0022-3514.63.2.221

Gottman, J. M., \& Notarius, C. I. (2002). Marital research in the 20th century and a research agenda for the 21st century. Family Process, 41, 159-197. https://doi.org/10.1111/j.1545-5300.2002.41203 .x

Hendrick, S. S. (1988). A generic measure of relationship satisfaction. Journal of Marriage and Family, 50, 93-98. https://doi.org/10.2307/352430

Johnson, M. D. (2002). The observation of specific affect in marital interactions: Psychometric properties of a coding system and a rating system. Psychological Assessment, 14, 423-438. https://doi .org/10.1037/1040-3590.14.4.423

Kanner, A. D., Coyne, J. C., Schaefer, C., \& Lazarus, R. S. (1981). Comparison of two modes of stress measurement: Daily hassles and uplifts versus major life events. Journal of Behavioral Medicine, 4, 1-39. https://doi.org/ https://doi.org/10.1007/ BF00844845

Kenny, D. A., \& Cook, W. (1999). Partner effects in relationship research: Conceptual issues, analytic difficulties, and illustrations. Personal Relationships, 6, 433-448. https://doi.org/10.1111/j.14756811.1999.tb00202.x

Kenny, D. A., Kashy, D. A., \& Cook, W. L. (2006). Dyadic data analysis. New York, NY: Guilford Press.

Kouros, C. D., Papp, L. M., Goeke-Morey, M. C., \& Cummings, E. M. (2014). Spillover between marital quality and parent-child relationship quality: Parental depressive symptoms as moderators. Journal of Family Psychology, 28, 315-325. https://doi.org/10.1037/a0036804

Kuster, M., Bernecker, K., Backes, S., Brandstätter, V., Nussbeck, F. W., Bradbury, T. N., . . . Bodenmann, G. (2015). Avoidance orientation and 
the escalation of negative communication in intimate relationships. Journal of Personality and Social Psychology, 109, 262-275. https://doi.org/ 10.1037/pspi0000025

Lavner, J. A., \& Bradbury, T. N. (2010). Patterns of change in marital satisfaction over the newlywed years. Journal of Marriage and the Family, 72, 1171-1187. https://doi.org/10.1111/j.1741-3737 .2010.00757.x

Lawrence, E., Rothman, A. D., Cobb, R. J., \& Bradbury, T. N. (2010). Marital satisfaction across the transition to parenthood: Three eras of research. In M. S. Schulz, M. K. Pruett, P. K. Kerig, \& R. D. Parke (Eds.), Strengthening couple relationships for optimal child development: Lessons from research and intervention (pp. 97-114). Washington, DC: American Psychological Association.

Ledermann, T., Bodenmann, G., \& Cina, A. (2007). The efficacy of the Couples Coping Enhancement Training (CCET) in improving relationship quality. Journal of Social and Clinical Psychology, 26, 940-959. https://doi.org/10.1521/jscp.2007.26.8 .940

Ledermann, T., Bodenmann, G., Rudaz, M., \& Bradbury, T. N. (2010). Stress, communication, and marital quality in couples. Family Relations, 59, 195-206. https://doi.org/10.1111/j.1741-3729 .2010.00595.x

Ledermann, T., Macho, S., \& Kenny, D. A. (2011). Assessing mediation in dyadic data using the actor-partner interdependence model. Structural Equation Modeling: A Multidisciplinary Journal, 18, 595-612. https://doi.org/10.1080/10705511 .2011 .607099

MacKinnon, D. P. (2008). Introduction to statistical mediation analysis. New York, NY: Routledge.

McHale, J. P., \& Lindahl, K. M. (2011). Coparenting: A conceptual and clinical examination of family systems (Vol. 12). Washington, DC: American Psychological Association.

McHale, J. P., Salman-Engin, S., \& Coovert, M. D. (2015). Improvements in unmarried African American parents' rapport, communication, and problem-solving following a prenatal coparenting intervention. Family Process, 54, 619-629. https:// doi.org/10.1111/famp.12147

McHale, S. M., \& Huston, T. L. (1985). The effect of the transition to parenthood on the marriage relationship: A longitudinal study. Journal of Family Issues, 6, 409-433. https://doi.org/10.1177/ 019251385006004002

Medina, A. M., Lederhos, C. L., \& Lillis, T. A. (2009). Sleep disruption and decline in marital satisfaction across the transition to parenthood. Families, Systems, \& Health, 27, 153-160. https://doi.org/10 $.1037 / \mathrm{a} 0015762$

Minuchin, P. (1985). Families and individual development: Provocations from the field of family therapy. Child Development, 56, 289-302. https:// doi.org/10.2307/1129720

Mitnick, D. M., Heyman, R. E., \& Smith Slep, A. M. (2009). Changes in relationship satisfaction across the transition to parenthood: A meta-analysis. Journal of Family Psychology, 23, 848-852. https: //doi.org/10.1037/a0017004

Muthén, L. K., \& Muthén, B. O. (1998-2015). Mplus user's guide (Version 7.2). Los Angeles, CA: Author.

Neff, L. A., \& Karney, B. R. (2007). Stress crossover in newlywed marriage: A longitudinal and dyadic perspective. Journal of Marriage and Family, 69, 594-607. https://doi.org/10.1111/j.1741-3737 .2007.00394.x

Nelson, J. A., O'Brien, M., Blankson, A. N., Calkins, S. D., \& Keane, S. P. (2009). Family stress and parental responses to children's negative emotions: Tests of the spillover, crossover, and compensatory hypotheses. Journal of Family Psychology, 23, 671-679. https://doi.org/10.1037/a0015977

Nelson, S. K., Kushlev, K., \& Lyubomirsky, S. (2014). The pains and pleasures of parenting: When, why, and how is parenthood associated with more or less well-being? Psychological Bulletin, 140, 846-895. https://doi.org/10.1037/a003 5444

Papp, L. M., Cummings, E. M., \& Goeke-Morey, M. C. (2009). For richer, for poorer: Money as a topic of marital conflict in the home. Family Relations, 58, 91-103. https://doi.org/10.1111/j.1741-3729 .2008.00537.x

Randall, A. K., \& Bodenmann, G. (2009). The role of stress on close relationships and marital satisfaction. Clinical Psychology Review, 29, 105-115. https://doi.org/10.1016/j.cpr.2008.10.004

Repetti, R. L., \& Wood, J. (1997). Effects of daily stress at work on mothers' interactions with preschoolers. Journal of Family Psychology, 11, 90-108. https://doi.org/10.1037/0893-3200. 11.1 .90

Sander, J., \& Böcker, S. (1993). Die Deutsche Form der Relationship Assessment Scale (RAS): Eine kurze Skala zur Messung der Zufriedenheit in einer Partnerschaft [The German version of the Relationship Assessment Scale (RAS): A short scale for measuring satisfaction in a dyadic relationship]. Diagnostica, 39, 55-62.

Sanders, M. R. (1999). Triple P-Positive Parenting Program: Towards an empirically validated multilevel parenting and family support strategy for the prevention of behavior and emotional problems in children. Clinical Child and Family Psychology Review, 2, 71-90. https://doi.org/10.1023/A: 1021843613840

Shrout, P. E., \& Bolger, N. (2002). Mediation in experimental and nonexperimental studies: New procedures and recommendations. Psychological 
Methods, 7, 422-445. https://doi.org/10.1037/10 82-989X.7.4.422

Story, L. B., \& Bradbury, T. N. (2004). Understanding marriage and stress: Essential questions and challenges. Clinical Psychology Review, 23, 1139-1162. https://doi.org/10.1016/j.cpr.2003.10. 002

Stroud, C. B., Durbin, C. E., Wilson, S., \& Mendelsohn, K. A. (2011). Spillover to triadic and dyadic systems in families with young children. Journal of Family Psychology, 25, 919-930. https://doi.org/ 10.1037/a0025443

Twenge, J. M., Campbell, W. K., \& Foster, C. A. (2003). Parenthood and marital satisfaction: A meta-analytic review. Journal of Marriage and Family, 65, 574-583. https://doi.org/10.1111/j $.1741-3737.2003 .00574 . x$
Webster-Stratton, C. (1990). Stress: A potential disruptor of parent perceptions and family interactions. Journal of Clinical Child Psychology, 19, 302-312. https://doi.org/10.1207/s15374424j ccp1904_2

Zemp, M., Milek, A., Cummings, E. M., Cina, A., \& Bodenmann, G. (2016). How couple- and parenting-focused programs affect child behavioral problems: A randomized controlled trial. Journal of Child and Family Studies, 25, 798-810. https://doi.org/10.1007/s10826-015-0260-1

Zemp, M., Milek, A., Davies, P. T., \& Bodenmann, G. (2016). Improved child problem behavior enhances the parents' relationship quality: A randomized trial. Journal of Family Psychology, 30, 896-906. https://doi.org/10.1037/fam0000212 